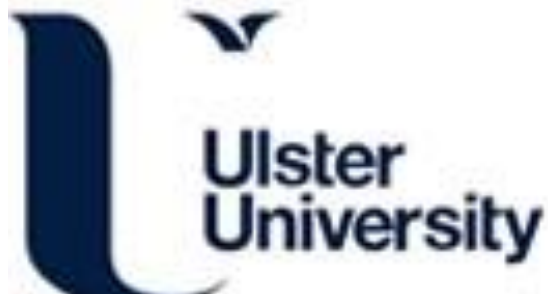

\section{Spatial Localization of Vitamin D Metabolites in Mouse Kidney by Mass Spectrometry Imaging}

Smith, K., Flinders, B., Thompson, P., Cruickshank, F., MacKay, L., Heeren, R., \& Cobice, D. (2020). Spatial Localization of Vitamin D Metabolites in Mouse Kidney by Mass Spectrometry Imaging. ACS Omega, 5(22), 13430-13437. https://doi.org/10.1021/acsomega.0c01697

Link to publication record in Ulster University Research Portal

Published in:
ACS Omega

Publication Status:

Published (in print/issue): 09/06/2020

DOI:

10.1021/acsomega.0c01697

Document Version

Publisher's PDF, also known as Version of record

\section{General rights}

Copyright for the publications made accessible via Ulster University's Research Portal is retained by the author(s) and / or other copyright owners and it is a condition of accessing these publications that users recognise and abide by the legal requirements associated with these rights.

\section{Take down policy}

The Research Portal is Ulster University's institutional repository that provides access to Ulster's research outputs. Every effort has been made to ensure that content in the Research Portal does not infringe any person's rights, or applicable UK laws. If you discover content in the Research Portal that you believe breaches copyright or violates any law, please contact pure-support@ulster.ac.uk. 


\title{
Spatial Localization of Vitamin D Metabolites in Mouse Kidney by Mass Spectrometry Imaging
}

\author{
Karl W. Smith, Bryn Flinders, Paul D. Thompson, Faye L. Cruickshank, C. Logan Mackay, \\ Ron M. A. Heeren, and Diego F. Cobice*
}

Cite This: https://dx.doi.org/10.1021/acsomega.0c01697

SI Supporting Information

ABSTRACT: Vitamin D plays a key role in the maintenance of calcium/phosphate homeostasis and elicits biological effects that are relevant to immune function and metabolism. It is predominantly formed through UV exposure in the skin by conversion of 7dehydrocholsterol (vitamin D3). The clinical biomarker, 25hydroxyvitamin D (25-(OH)-D), is enzymatically generated in the liver with the active hormone 1,25-dihydroxyvitamin $\mathrm{D}$ then formed under classical endocrine control in the kidney. Vitamin D metabolites are measured in biomatrices by liquid chromatography-tandem mass spectrometry (LC-MS/MS). In LC-MS/MS, chemical derivatization (CD) approaches have been employed to achieve the desired limit of quantitation. Recently, matrix-assisted laser desorption/ ionization (MALDI) has also been reported as an alternative method.

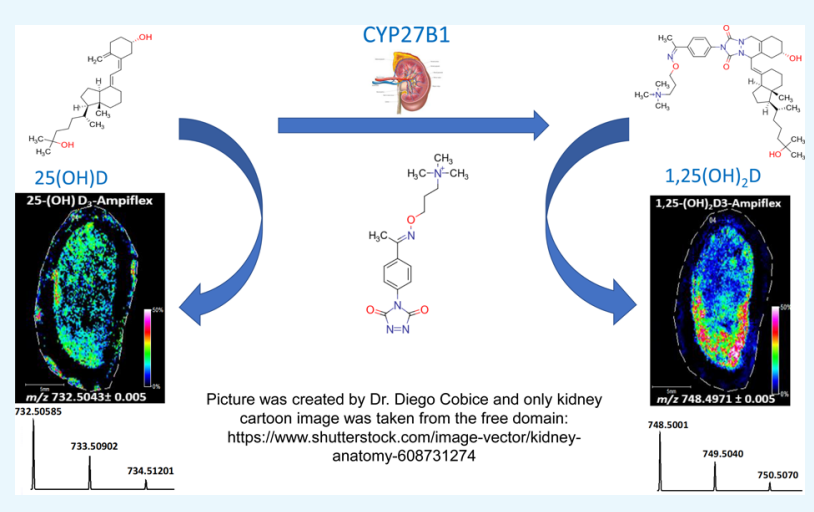
However, these quantitative approaches do not offer any spatial information. Mass spectrometry imaging (MSI) has been proven to be a powerful tool to image the spatial distribution of molecules from the surface of biological tissue sections. On-tissue chemical derivatization (OTCD) enables MSI to image molecules with poor ionization efficiently. In this technical report, several derivatization reagents and OTCD methods were evaluated using different MSI ionization techniques. Here, a method for detection and spatial distribution of vitamin $\mathrm{D}$ metabolites in murine kidney tissue sections using an OTCD-MALDI-MSI platform is presented. Moreover, the suitability of using the Bruker ImagePrep for OTCDbased platforms has been demonstrated. Importantly, this method opens the door for expanding the range of other poor ionizable molecules that can be studied by OTCD-MSI by adapting existing CD methods.

\section{INTRODUCTION}

Vitamin D has become a priority area of research worldwide. It is a vital component for a number of biological processes such as calcium homeostasis ${ }^{1}$ and immune function. ${ }^{2}$ The hormone is studied not only from the aspect of vitamin D deficiency against diseases such as rickets or osteoporosis ${ }^{3,4}$ but also as a potential treatment of diseases including cancer and mental disorders. $^{5-8}$ Vitamin D is mainly formed through UV exposure to the skin, through conversion of 7-dehydrocholesterol to the metabolite vitamin $\mathrm{D}_{3}$ but can also be supplied via vitamin-D-sourced foods as vitamin $\mathrm{D}_{2} \cdot{ }^{9-11}$ The precursor is metabolized in the liver via enzymatic hydroxylation to produce 25-hydroxyvitamin D (25-(OH)-D), a clinical biomarker. Further hydroxylation is then carried out in the kidney, producing the active hormone $1 \alpha, 25$-dihydroxyvitamin D $\left(1,25-(\mathrm{OH})_{2}-\mathrm{D}\right)$, known to be the active ligand of the vitamin $\mathrm{D}$ receptor protein and elicits transcriptional effects. $^{12,13}$ Vitamin D metabolites are primarily measured in biomatrices by immunoassays or liquid chromatographytandem mass spectrometry (LC-MS/MS). ${ }^{14}$ Steroidal class compounds are known to have poor ionization efficiency in mass spectrometry (MS) because of a lack of ionizable moieties. To overcome this issue, chemical derivatization (CD) approaches have been used in LC-MS/MS-based platforms using both electrospray ionization (ESI) and atmospheric pressure chemical ionization. ${ }^{15,16} \mathrm{CD}$ is intended to increase the ionization efficiency by tackling ion suppression effects and potential isobaric interferences. Recently, it has been shown that vitamin $\mathrm{D}$ metabolites, with the aid of $\mathrm{CD}$, can be detected and quantified by matrix-assisted laser desorption/ionization (MALDI). ${ }^{17}$ These methods are primarily being used to assess levels of vitamin $\mathrm{D}$ metabolites in clinical settings. MS is currently being used to measure vitamin $\mathrm{D}$ metabolites in serum/plasma and tissue homogenate samples. These quantitative approaches, however, do not

Received: April 13, 2020

Accepted: May 13, 2020 

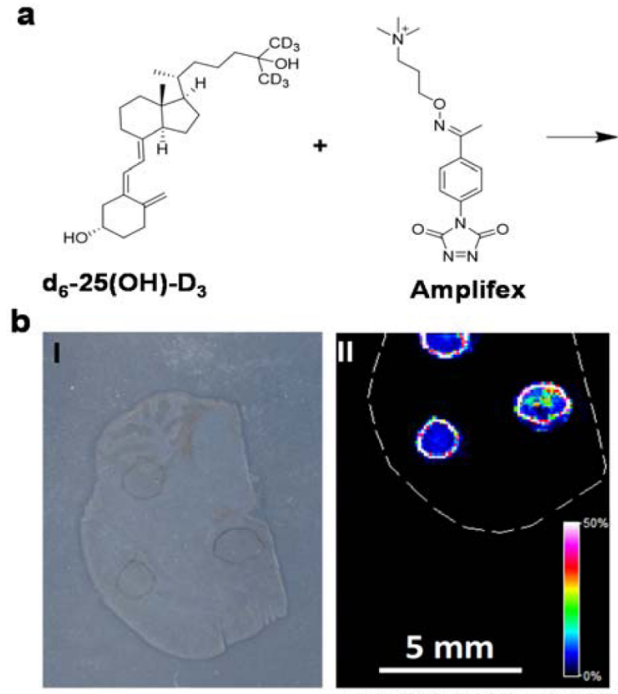

Amplifex

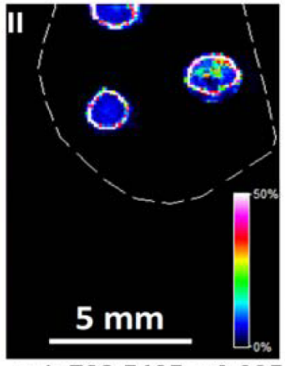

$m / 2738.5435 \pm 0.005$

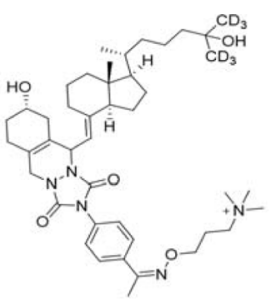

$d_{6}-25(\mathrm{OH})-D_{3}$ derivative

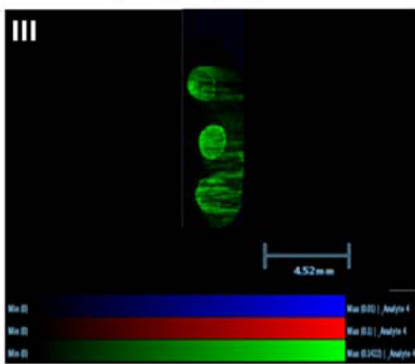

$m / z 738.5435 \pm 0.005$

C

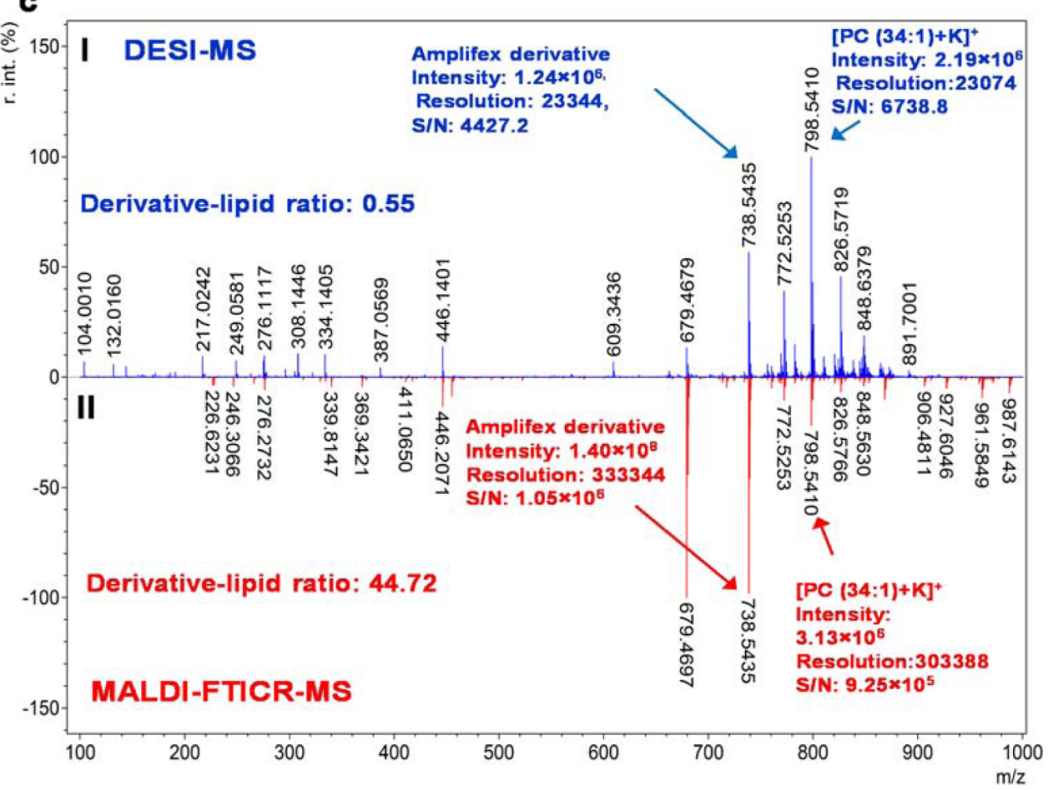

Figure 1. On-tissue spotting experiments by MALDI and DESI MSI platforms using Amplifex as a derivatization reagent. (a) Vitamin D-Amplifex derivatization reaction scheme and (b) on-tissue spotting experiments. (I) Optical image of control tissue section (II) MALDI-MSI molecular distribution map of spotted $d_{6}-25-(\mathrm{OH})-\mathrm{D}_{3}$ Amplifex derivative at $m / z 738.5435 \pm 0.005$. (III) DESI-MSI molecular distribution map of spotted ISTD vitamin D standard Amplifex derivative at $m / z 738.5435 \pm 0.005$; (c) representative zoomed-out single-pixel mass spectrum of $d_{6}-25$ - $(\mathrm{OH})$ $\mathrm{D}_{3}$-Amplifex derivative spotted region using (I) DESI-qTOF-MS. (II) MALDI-FTICR-MS both with a mass accuracy of 1.08 ppm against theoretical monoisotopic mass. Data were normalized to TIC. Spatial resolution was set at $100 \mu \mathrm{m}$, with scale bars shown. Signal intensity is depicted by color on the scale shown. Spectrum was postcalibrated to CHCA cluster matrix ion at $+\mathrm{ve} m / z 417.0483$.

offer any spatial information. Mass spectrometry imaging (MSI) enables the ability to gain spatial information of various molecules with spectra being mapped to individual pixels. Molecules can be localized and quantified to a host of different organ/tissue types. On-tissue chemical derivatization (OTCD) is enabling MSI to push the boundary of poor ionizable molecules to be imaged within tissues by increasing signal intensity, shifting $m / z$ values, and overcoming poor ionization performance. Previous studies have shown the use of several derivatization reagents in MSI applications. Some examples are Girard-T reagent targeting steroids ${ }^{18,19}$ and triamcinolone acetonide, ${ }^{20}$ pyrylium salts for primary amine moiety molecules, ${ }^{21}$ and $1,1^{\prime}$-thiocarbonyldiimidazole for 3-methoxysalicylamine. ${ }^{22}$ Other OTCD approaches have also been successfully trialed, such as a high-voltage electrospray deposition using 2-picolylamine for endogenous fatty acids in rat brain tissue. ${ }^{23}$

In this article, several derivatization reagents, deposition techniques, and reaction conditions were evaluated using different ionization techniques including MALDI and desorption electrospray ionization (DESI) to achieve best ion production yields in MSI analysis of vitamin D metabolites in murine tissue sections. For the first time, a method for detection and spatial distribution of vitamin $\mathrm{D}$ metabolites using an OTCD-MALDI-MS platform is presented. Specifically, endogenous $1,25-(\mathrm{OH})_{2}-\mathrm{D}_{3}$ and $25-(\mathrm{OH})-\mathrm{D}_{3}$ were detected within a mouse kidney using Amplifex as the derivatization reagent and results were confirmed by LC-MS/ MS. The suitability of Bruker's ImagePrep is also demonstrated 

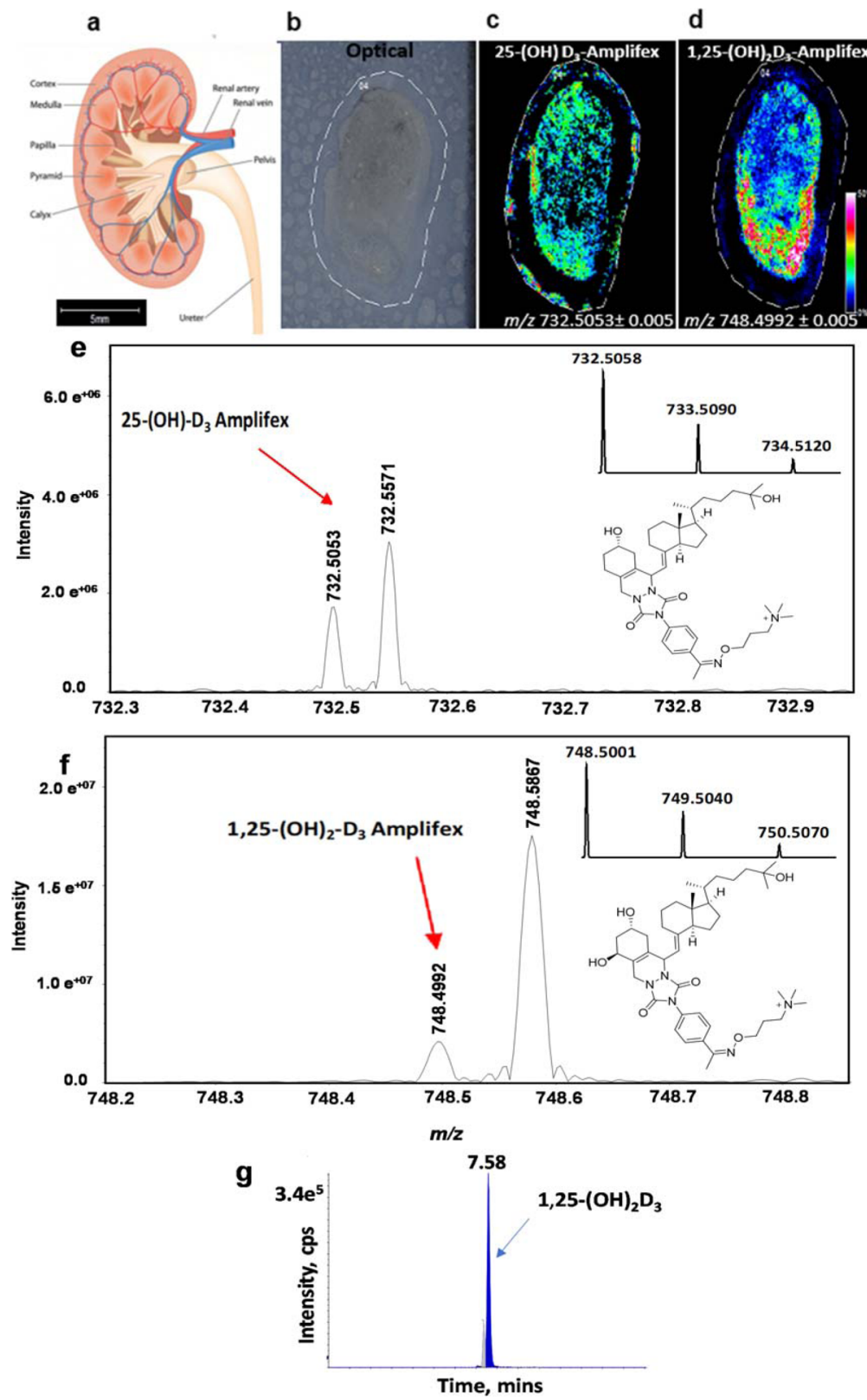

Figure 2. Molecular distribution of endogenous vitamin D metabolites detected as Amplifex derivatives in a mouse kidney section using the optimized and automated OTCD-MALDI-MSI platform. (a) Illustration of a kidney section; (b) optical image of mouse kidney; (c) molecular distribution map of $25-\mathrm{OH}-\mathrm{D}_{3}$-Amplifex derivative $(\mathrm{m} / z 732.5053 \pm 0.005)$; (d) molecular distribution map of $1,25-(\mathrm{OH})_{2}$ - $\mathrm{D}_{3}$-Amplifex derivative $(m / z 748.4992 \pm 0.005)$; and (e) representative single-pixel MALDI-FTICR-MS mass spectrum for $25-(\mathrm{OH})-\mathrm{D}_{3}$-Amplifex derivative with a mass accuracy of $0.68 \mathrm{ppm}$ against theoretical monoisotopic mass (shown inset). (f) Representative single-pixel MALDI-FTICR-MS mass spectrum for 1,25- $(\mathrm{OH})_{2}$-D3-Amplifex derivative with a mass accuracy of $1.20 \mathrm{ppm}$ against theoretical monoisotopic mass (shown inset). (g) Active metabolite $\left(1-25-(\mathrm{OH})_{2}-\mathrm{D}_{3}\right)$ confirmation by LC-MS/MS. Data were normalized to TIC. Spatial resolution was analyzed at $100 \mu \mathrm{m}$, with scale bars shown. Signal intensity is depicted by color on the scale shown. Spectrum was postcalibrated to CHCA cluster matrix ion at + ve $m / z$ 417.0483 .

for an automated and robust method for OTCD-MSI applications.

\section{RESULTS AND DISCUSSION}

Reagent Screening and lonization Assessment (OffTissue). This novel application of OTCD coupled with MSI permits detection of endogenous vitamin $\mathrm{D}$ metabolites within tissues by generating permanently charged derivatives which yielded intense signals upon MALDI-Fourier transform ion cyclotron resonance mass spectrometry (FTICR)-MSI analysis. The spatial distribution of both $25-(\mathrm{OH})-\mathrm{D}_{3}$ and
$1,25-(\mathrm{OH})_{2}-\mathrm{D}_{3}$ in mouse kidney was assessed. This technique has the potential to be applied to other vitamin $\mathrm{D}$ metabolites to investigate vitamin $\mathrm{D}$ intracrinology in multiple biological tissues.

In this article, several LC-MS-based derivatization reagents were evaluated using the reaction conditions to investigate the performance in different MSI ionization modes, specifically MALDI and DESI. These reagents (PTAD, DMEQ-TAD, and Amplifex (Figure S1) were screened off, and on-tissue with instrument parameters optimized using a stable isotope of vitamin $\mathrm{D}\left(d_{6}\right.$-25-hydroxyvitamin- $\left.\mathrm{D}_{3}\left(d_{6}-25-(\mathrm{OH})-\mathrm{D}_{3}\right)\right)$ as an 


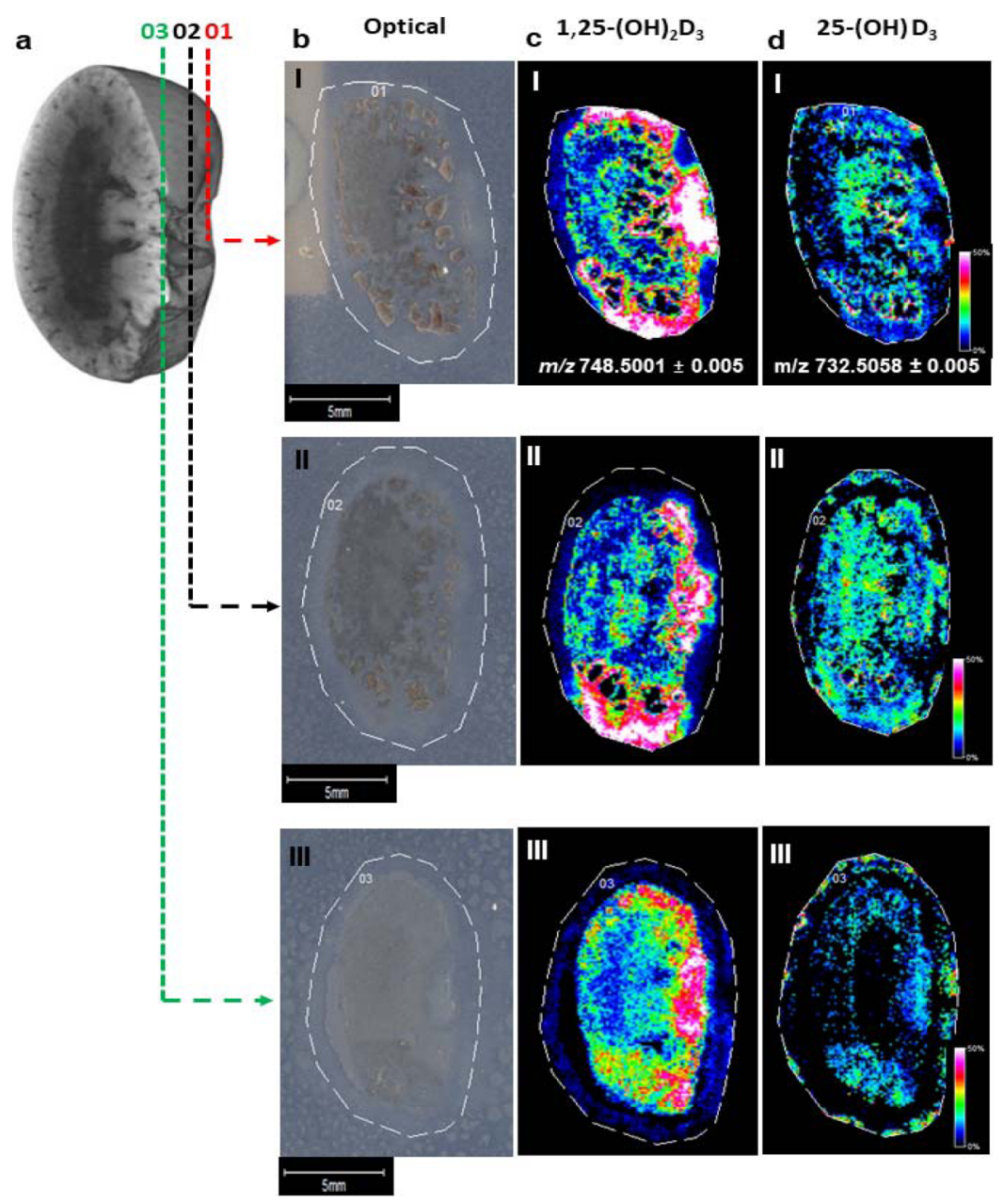

Figure 3. Molecular distribution assessment of endogenous vitamin D metabolites detected as Amplifex derivatives on three adjacent sections of mouse kidney using the optimized and automated OTCD-MALDI-MSI platform. (a) Illustration of a kidney section. [ $b(\mathrm{I}, \mathrm{II})]$ Optical images of adjacent mouse kidney. [c(I,III)] Molecular distribution map of 1-25- $(\mathrm{OH})_{2}-\mathrm{D}_{3}$-Amplifex derivative $(\mathrm{m} / z$ 748.5001 \pm 0.005$)$. [d(I-III)] Molecular distribution map of $25-(\mathrm{OH})-\mathrm{D}_{3}$-Amplifex derivative $(\mathrm{m} / z 732.5058 \pm 0.005)$. Data were normalized to TIC. Spatial resolution was analyzed at $100 \mu \mathrm{m}$, with scale bars shown. Signal intensity is depicted by the color on the scale shown.

internal standard (ITSD). During off-tissue ionization evaluation, the derivatized PTAD metabolite displayed no fingerprint signal across any of the investigated ionization methods, indicating that PTAD is not suitable for MALDI or DESI analysis. The Amplifex ISTD derivative was detected using both MALDI-MS at $m / z 738.5437 ; 0.27 \mathrm{ppm}$ mass accuracy; $1.8 \times 10^{8}$ signal intensity; and signal/noise $(\mathrm{S} / \mathrm{N})$ of $3.1 \times 10^{8}$ (Figure S2b) and DESI-MS at $m / z 738.5447 ; 1.62$ ppm mass accuracy; $1.1 \times 10^{7}$ signal intensity; and $\mathrm{S} / \mathrm{N}$ of 1.7 $\times 10^{6}$ (Figure S2c). DMEQ-TAD derivative was also detected using MALDI-MS at $m / z 752.4863 ; 0.12$ ppm mass accuracy; $7.2 \times 10^{7}$ signal intensity; and S/N of $2.2 \times 10^{5}$ (Figure S3b) and DESI-MS at $m / z 752.4843 ; 2.78$ ppm mass accuracy; 2.5 $\times 10^{5}$ signal intensity; and $\mathrm{S} / \mathrm{N}$ of 1342 (Figure S3c). As expected, Amplifex outperformed DMEQ-TAD in terms of ion signal production for vitamin $\mathrm{D}$ metabolite derivatives in positive ion mode, primarily because of its positively charged quaternary amine moiety.

On-Tissue Spotting Assessment, Amplifex Reaction Conditions, and OTCD Sample Preparation Optimization. Based on the off-tissue screening results, Amplifex and DMEQ-TAD were selected as suitable reagents for an ontissue ion suppression assessment. On-tissue ionization suppression was conducted as described in Supporting
Information Section 1.2 using a control (blank) tissue section (Figure 1). Amplifex derivative was detected on tissue in MALDI-MSI [Figure $1 \mathrm{c}(\mathrm{II})$ ] at $\mathrm{m} / z$ 738.5435; $0.01 \mathrm{ppm}$ mass accuracy; $1.4 \times 10^{8}$ signal intensity; and S/N $1.05 \times 10^{6}$ (Figure 1c). Using DESI-MSI (Figure 1cI), the Amplifex derivative was detected at $\mathrm{m} / z$ 738.5435; $0.01 \mathrm{ppm}$ mass accuracy, with a signal intensity of $1.24 \times 10^{6}$, and $\mathrm{S} / \mathrm{N}$ of 4427.

The DMEQ-TAD derivative was also detected by MALDIMSI at $m / z 752.4848 ; 2.11 \mathrm{ppm}$ mass accuracy with a signal intensity of $6.3 \times 10^{7}$; and S/N of $1.2 \times 10^{4}$ (Figure S4) and DESI-MSI at $m / z 752.4730 ; 1.7$ ppm mass accuracy, signal intensity around $0.8 \times 10^{4}$, and S/N of 340 (Figure S5). Ontissue Amplifex and DMEQ-TAD VitD derivatives showed good ionization in both the MALDI and DESI-MSI platforms with best results achieved using the Amplifex-MALDI-MSI platform. Analyte diffusion was observed during DESI-MSI, which may be related to solvent spraying and charging effects caused by the chemical nature of the derivatization reagent. Based on the results obtained from on-tissue screening experiments, MALDI-MSI using Amplifex as a derivatization reagent was selected as the imaging platform for final reaction and sample preparation optimization. Off- and on-tissue reaction parameters were evaluated with an optimal $\mathrm{CD}$ 
condition achieved at $1 \mathrm{~h}$ at room temperature (RT) for both off-tissue (Figure S6a) and on-tissue derivatization (Figure S6b). Regarding reagent deposition and OTCD, two methods were evaluated for MSI performance in terms of analyte detection, diffusion, and reproducibility. The Bruker ImagePrep and a commercial artistic airbrush were assessed. The airbrush application method was adapted from previous studies, $^{23}$ and the Bruker ImagePrep method was adapted and customized for reagent deposition as described in the Materials and Methods section "OTCD-MSI Analysis of Endogenous Vitamin D Metabolite Derivatives in Mouse Kidney Tissue Sections". Figure S7 clearly shows that the automated ImagePrep method outperformed the manual airbrush. Ion signal intensity was increased in the ImagePrep MS images, as better $\mathrm{S} / \mathrm{N}$ ratios (ImagePrep 2800 and airbrush 1200) were obtained than with the airbrush method (Supporting Information Figure S7d). Moreover, tissue-totissue reproducibility and analyte diffusion were improved by using the Bruker ImagePrep approach (Figure S7d).

When using manual sample preparation methods, analyst-toanalyst variations have a negative impact on reproducibility in MS and particularly with MSI analysis. These parameters in manual OTCD methods are very difficult to control. On the contrary, these potential issues are well controlled in the automated method as both reagent application and CD reaction can be carried out using the same device. In this method, several key parameters can be controlled such as drying, incubation time, and spray frequency. Another advantage of the automated ImagePrep is that both application and derivatization reaction are performed under an inert atmosphere, allowing oxygen-sensitive chemical reactions to be carried out robustly. However, one disadvantage to mention is that in the ImagePrep, temperature cannot be controlled and thus would not be applicable to OTCD reactions that require controlled temperatures.

Distribution of Endogenous Vitamin D Metabolites in Mouse Kidney Tissue by OTCD-MALDI-FTICR-MSI. For the first time, vitamin D metabolites were successfully detected, and their spatial distribution was assessed in murine kidney tissue sections using the optimized automated OTCDMALDI-MSI platform. Hydroxylation of the precursor 25hydroxyvitamin $\mathrm{D}$ occurs in the kidney to produce the active metabolite, 1,25-dihydroxyvitamin $\mathrm{D}$, by the enzyme CYP27B1. ${ }^{28,29}$ Therefore, this gives a good rationale for the selection of the kidney as a target/suitable metabolic tissue to perform this MSI feasibility study.

As shown in Figure 2, two endogenous vitamin D metabolites were detected as Amplifex derivatives at $\mathrm{m} / z$ 732.5053 , corresponding to the $25-(\mathrm{OH})-\mathrm{D}_{3}$ (Figure $2 \mathrm{c}$ ) and $m / z 748.4992$ for $1,25-(\mathrm{OH})_{2}-\mathrm{D}_{3}$ (Figure $2 \mathrm{~d}$ ), with a mass accuracy of $0.68 \mathrm{ppm}$ (Figure 2e) and $1.20 \mathrm{ppm}$ (Figure 2f), against their theoretical monoisotopic protonated masses, respectively. To confirm the identification of the active metabolite 1,25- $(\mathrm{OH})_{2}-\mathrm{D}_{3}$, collision-induced dissociation (CID) experiments were performed on high signal intensity region of interests (ROI) within the tissue section. The CID on the $\mathrm{M}^{+}$ion at $m / z 748.49$ showed a main fragment at $m / z$ 689.4493 with a loss of $59 \mathrm{Da}$ corresponding to the trimethylamine moiety (Figure S8). These results are in agreement with previous literature reports. ${ }^{17} \mathrm{LC} / \mathrm{MS}$ was also performed to confirm the presence of the active metabolite $\left(1,25-(\mathrm{OH})_{2}-\mathrm{D}_{3}\right)$ on the tissue homogenate, giving a concentration of $132.6 \mathrm{pg} / \mathrm{g}$ (Figure $2 \mathrm{~g}$ ).
To study the molecular distribution pattern of vitamin D metabolites across the mouse kidney, the molecular mapping of three sections were assessed. As shown in Figure 3, 1,25$(\mathrm{OH})_{2}-\mathrm{D}_{3}$ was mainly detected across the cortex gathering near the renal vein and $25-(\mathrm{OH})-\mathrm{D}_{3}$ was mainly distributed across the medulla and inner cortex. However, as shown in Figure 3, the $25-(\mathrm{OH})-\mathrm{D}_{3}$ metabolite formation was depthdependent, as its normalized signal intensity varies across a series of adjacent kidney sections $(n=3)$, with the detected signal decreasing throughout the tissue. This suggests that $3 \mathrm{D}$ molecular mapping analysis may provide valuable information regarding metabolism across the entire tissue. Knowing the tissue distribution of vitamin $\mathrm{D}$ metabolites may be key in the understanding of the synthesis and function of the active metabolite $1,25-(\mathrm{OH})_{2}-\mathrm{D}_{3}$ as it has a key role in the calcium absorption and it is a potent ligand in gene transcription pathways across various tissues. ${ }^{9,30}$ Previous studies have detected the CYP27B1 enzyme by immunohistochemistry in the proximal tubules of kidney nephrons, located in the cortex region of the tissue. ${ }^{31}$ In vivo pharmacokinetics and pharmacodynamics experiments using stable isotope tracers in combination with MSI might be able to expand the knowledge of vitamin $\mathrm{D}$ metabolism by understanding the biology of vitamin D and the CYP27B1 enzyme activity at tissue-specific levels.

Quantitative MSI Feasibility. A VitD metabolite-stable isotope (deuterium labeled, $d_{2}$ ) was used in this study as an ISTD for method development purposes, and it is currently commercially available. Therefore, quantitative MSI (qMSI) of VitD metabolites would be achievable by applying well-known models such as mimetic tissue, tissue extinction coefficient, and standard on-tissue spotting. Because VitD metabolites are endogenously present in key metabolic tissues such as kidney, a potential qMSI approach is to use a calibration based on a range of known deuterated labeled VitD solutions (used as standards) with a fixed amount of a ${ }^{13} \mathrm{C}$ labeled (as an ISTD) spiked onto a series of tissue homogenates. As the ionization is mainly driven by the derivatization reagent quaternary amine moiety, it would be valid to assume that the response factors of all Amplifex-VitD derivatives will be close to 1 . In this case, the more conservative and accurate qMSI approach would be to use the mimetic tissue method as it would minimize any topology-related effects, usually observed during manual or automated tissue-spotting approaches. Analysis could be performed using $\mathrm{VitD}\left(d_{2} /{ }^{13} \mathrm{C}\right)$ ratios containing pixels employing three replicates and two MSI platforms such as MALDI-TOF-qMSI and MALDI-FTICR-qMSI. The average intensity of each layer of the mimetic tissue model can be correlated with the known spiked concentration to generate a calibration curve. This curve can then be used to quantify ROIs on the target tissue. These results will be compared to the conventional gold standard quantitative platform using HPLC-MS/MS. For calculations, linear or nonlinear regression analysis can be used depending on factors such as matrix-to-analyte ratio, nonuniform tissue-ion suppression, interferences from matrix background signals, and different ion detection/counting technologies.

\section{CONCLUSIONS}

MSI with OTCD is a powerful new tool to study the spatial distribution of vitamin $\mathrm{D}$ metabolites within tissues. This is the first technique capable of detecting and potentially quantifying low physiological endogenous tissue levels of vitamin D 
metabolites. qMSI using stable isotope standards would be achieved by applying well-established qMSI approaches. We have demonstrated its utility for measuring endogenous concentrations within murine kidney, a key metabolic organ for vitamin $\mathrm{D}$ metabolism. This offers the opportunity for many novel insights into tissue-specific vitamin D biology. Moreover, the suitability of using the automated ImagePrep for reagent deposition and as a reaction chamber for OTCD-based platforms shows a promising outcome and offers the ideal conditions to achieve reproducible MSI images. Importantly, the use of OTCD-MSI facilitates/enables the analysis of previously inaccessible biologically relevant molecules through adaptation of existing CD methods.

\section{MATERIALS AND METHODS}

Sources of Chemicals. ISTD 26,26,26,27,27,27-D $-25-$ hydroxyvitamin $\mathrm{D}_{3}\left(d_{6}-25-(\mathrm{OH})-\mathrm{D}_{3}\right)$, Amplifex Diene reagent, 4-phenyl-1,2,4-trazoline-3,5-dione (PTAD), and $\alpha$-cyano-4hydroxycinnamic acid (CHCA) were obtained from SigmaAldrich (UK). 1 $\alpha, 25$-Dihydroxyvitamin $\mathrm{D}_{3}\left(1,25-(\mathrm{OH})_{2}-\mathrm{D}_{3}\right)$ was obtained from Enzo Life Sciences (UK). 4-(2-(6,7Dimethoxy-4-methyl-3-oxo-3,4-dihydroquinoxalinyl)ethyl)1,2,4-triazoline-3,5-dione reagent (DMEQ-TAD) was purchased from Abcam (UK). Solvents were of HPLC grade from Fisher Scientific (UK).

Animal and Tissue Collection. Experiments were conducted in accordance with the Animal (Scientific Procedures) Act 1986. Male nude CD-1 mice (aged 6-8 weeks, weighing approximately $27-34 \mathrm{~g}$ ) were housed at a RT of $20-24{ }^{\circ} \mathrm{C}$, with a $12 \mathrm{~h}$ light/dark cycle. Animals were housed in individually ventilated cages with standard certified diet food and water provided ad libitum. Animals were sacrificed by schedule I. Organs were then extracted and snapfrozen in liquid nitrogen and stored at $-80{ }^{\circ} \mathrm{C}$ until MSI analysis.

Tissue Sectioning and Mounting. Tissues were cryosectioned on a sagittal plane for brain tissue (control tissue for spotting experiments) and top-down (horizontal) section for mouse kidney $(12 \mu \mathrm{m})$. Sectioning was performed using a Leica cryostat model CM 1850 UV (Leica Biosystems, Nußloch, Germany). Sections were thaw-mounted onto conductive indium tin oxide-coated slides (Bruker Daltonics, Bremen, $\mathrm{GmbH}$ ), dried in a vacuum desiccator (RT, $30 \mathrm{~min}$ ), and then stored at $-80{ }^{\circ} \mathrm{C}$.

Off- and On-Tissue Method Development and Amplifex Reaction Condition Optimization. See the Supporting Information.

OTCD-MSI Analysis of Endogenous Vitamin D Metabolite Derivatives in Mouse Kidney Tissue Sections. At $-80{ }^{\circ} \mathrm{C}$, tissue sections were dried in a vacuum desiccator $(20 \mathrm{~min})$. Amplifex reagent $(5 \mathrm{~mL}, 0.1 \mathrm{mg} / \mathrm{mL}$ in $50: 50 \mathrm{v} / \mathrm{v}$ acetonitrile/water) was applied to the tissue sections by ImagePrep (Bruker Daltonics, Bremen, $\mathrm{GmbH}$ ). The ImagePrep parameters were set as follows: "matrix thickness": 40 cycles, spray power: $25 \%$, and a fixed spray time of $2.2 \mathrm{~s}$. Incubation was set to $30 \mathrm{~s}$ with a fixed dry time of $60 \mathrm{~s}$, leading to a final OTCD time of $60 \mathrm{~min} / \mathrm{slide}$ with a reagent density of $0.02 \mathrm{mg} / \mathrm{cm}^{2}$. An artistic airbrush was also evaluated as an OTCD method adapted from Cobice et al. ${ }^{24}$ Briefly, a reaction solution of Amplifex ( $2 \mathrm{~mL}, 0.25 \mathrm{mg} / \mathrm{mL}$ in $50: 50 \mathrm{v} / \mathrm{v}$ acetonitrile/water) was sprayed positioned $20 \mathrm{~cm}$ away from the target with a $\mathrm{N}_{2}$ pressure of 1.2 bar. The reagent density was $0.02 \mathrm{mg} / \mathrm{cm}^{2}$. Then, the slide was placed in a closed reaction container, containing a $1: 1 \mathrm{v} / \mathrm{v}$ solution of acetonitrile/water and a moist Kimwipe under the lid and placed in an oven at $37{ }^{\circ} \mathrm{C}$ for $1 \mathrm{~h}$.

Matrix Application. CHCA $(6 \mathrm{~mL}, 5 \mathrm{mg} / \mathrm{mL}$ in $70: 30 \mathrm{v} / \mathrm{v}$ acetonitrile/water $+0.1 \% \mathrm{v} / \mathrm{v}$ TFA) was applied in four passes using a $3 \mathrm{D}$ printer, as described in Tucker et al. ${ }^{25}$ A flow rate of $0.1 \mathrm{~mL} / \mathrm{min}$ with a gas pressure of $2 \mathrm{bar}$, a bed temperature of $30{ }^{\circ} \mathrm{C}$, a $z$-height of $30 \mathrm{~mm}$, and a velocity of $1100 \mathrm{~mm} / \mathrm{min}$ were achieved, averaging a run time of $24 \mathrm{~min}$ per slide. A uniform coating of matrix was achieved with $0.12 \mathrm{mg} / \mathrm{cm}^{2}$.

Instrumentation. Spotting assessment and MSI were performed using a 9.4 T SolariX MALDI-FTICR-MS (Bruker Daltonik GmbH, Bremen, Germany) employing a Smartbeam $2 \mathrm{kHz}$ laser, with instrument control using FTMS control v2.2.0 (build 150) FlexImaging version 5.1 (build 80) and data analysis using mMass software v5.5.0 for mass spectral postprocessing and recalibration. ${ }^{26,27}$ DESI-MSI experiments were performed on a commercial DESI 2D source (OmniSpray 2D Source, Prosolia Inc, Indianapolis, IN, USA) mounted on a Waters Xevo G2-XS quadrupole time of flight mass spectrometer (Waters Corporation, Manchester, UK). CD reaction optimization was performed on an Applied Biosystems/MDS Sciex 4800 MALDI TOF/TOF mass spectrometer (Foster City, California, USA) equipped with a neodymium-doped yttrium aluminum garnet (Nd:YAG) laser operating at $355 \mathrm{~nm}(200 \mathrm{~Hz}$ repetition rate). The mass range was acquired from 400 to $800 \mathrm{Da}$, focusing on the appropriate base peak ion in positive reflector mode. The instrument was calibrated using CAL MIX 5 as per manufacturer guidelines.

Confirmatory LC-MS/MS analysis was performed using a triple-quadrupole linear ion trap mass spectrometer (QTRAP 6500, AB Sciex, Cheshire, UK) coupled with an ACQUITY ultra-high-pressure liquid chromatography system (UHPLC; Waters, Manchester, UK).

MALDI-FTICR-MSI. MALDI-MSI was performed using a 9.4 T SolariX. The instrument was calibrated prior to analysis using red phosphorus clusters during method development and optimization operated in magnitude mode at $516 \mathrm{~K}$ size at a mass range of $m / z 600-900$ using one average scan in positive ion mode. Four hundred shots were accumulated per pixel/ spot at $2000 \mathrm{~Hz}$ frequency employing a minimum laser focus. Kidney section images were acquired using the optimized imaging method operated in constant accumulation of selected ion mode at $m / z 732$ (Q-isolation) with an isolation window of $100 \mathrm{Da}$ in positive ion mode. The mass resolution at $\mathrm{m} / z$ 700 was 40,000 . The same laser parameters were used as per the development method. Images were acquired at a spatial resolution of $100 \times 100 \mu \mathrm{m}$, generated using the FlexImaging version 5.1 software (Bruker Daltonik $\mathrm{GmbH}$ ), and then normalized with the total ion current (TIC). A 95\% data reduced profile spectrum and spectrum peak list were saved for further analysis. Optical images were taken using a flatbed scanner (Cannon LiDE-20, Cannon, UK). CID experiment on $1,25-(\mathrm{OH})_{2}-\mathrm{D}_{3}$ was performed at $m / z 748.49$ with an isolation window of $20 \mathrm{Da}$, isolation time of $2 \mathrm{~s}$, and 800 laser shots using $35 \mathrm{eV}$ collision energy.

DESI-MSI. See the Supporting Information.

Confirmatory LC-MS/MS Analysis. See the Supporting Information. 


\section{ASSOCIATED CONTENT}

\section{SI Supporting Information}

The Supporting Information is available free of charge at https://pubs.acs.org/doi/10.1021/acsomega.0c01697.

Method development including CD reaction conditions, ion suppression assessment, sample preparation optimization, VitD metabolites, off-tissue spotting experiments, on-tissue ionization assessment, VitD-Amplifex reaction conditions, optimization of OTCD, CID experiments, LC gradient, multiple reaction monitoring conditions, off-tissue reagent screening results, and ontissue ionization suppression assessment (PDF)

\section{AUTHOR INFORMATION}

\section{Corresponding Author}

Diego F. Cobice - Mass Spectrometry Centre, Biomedical Sciences Research Institute (BMSRI), School of Biomedical Sciences, Ulster University, Coleraine BT52 1SA, U.K.; (1) orcid.org/0000-0001-5283-2931;

Phone: +442892604456; Email: d.cobice@ulster.ac.uk

\section{Authors}

Karl W. Smith - Mass Spectrometry Centre, Biomedical Sciences Research Institute (BMSRI), School of Biomedical Sciences and The Nutrition Innovation Centre for Food and Health (NICHE), Biomedical Sciences Research Institute (BMSRI), School of Biomedical Sciences, Ulster University, Coleraine BT52 1SA, U.K.

Bryn Flinders - Dutch Screening Group, Maastricht 6229 GS, The Netherlands

Paul D. Thompson - The Nutrition Innovation Centre for Food and Health (NICHE), Biomedical Sciences Research Institute (BMSRI), School of Biomedical Sciences, Ulster University, Coleraine BT52 1SA, U.K.

Faye L. Cruickshank - Scottish Instrumentation and Research Centre for Advanced Mass Spectrometry (SIRCAMS), EaStCHEM School of Chemistry, Joseph Black Building, University of Edinburgh, Edinburgh EH9 3FJ, U.K.; (1) orcid.org/0000-0002-9582-5149

C. Logan Mackay - Scottish Instrumentation and Research Centre for Advanced Mass Spectrometry (SIRCAMS), EaStCHEM School of Chemistry, Joseph Black Building, University of Edinburgh, Edinburgh EH9 3FJ, U.K.; (1) orcid.org/0000-0003-1018-8353

Ron M. A. Heeren - Maastricht Multimodal Molecular Imaging Institute (M4I), University of Maastricht, Maastricht 6229 ER, The Netherlands; (1) orcid.org/0000-0002-65337179

Complete contact information is available at: https://pubs.acs.org/10.1021/acsomega.0c01697

\section{Author Contributions}

D.F.C. and R.M.A.H. conceived and coordinated the experiments. K.W.S., B.F., and D.F.C. designed the experiments. K.W.S., B.F., F.L.C., and C.L.M. carried out MS experiments. K.W.S., B.F., P.D.T., and D.F.C conducted data processing and analysis. K.W.S., B.F., and D.F.C. wrote the manuscript, which was edited by all co-authors.

\section{Notes}

The authors declare no competing financial interest.

\section{ACKNOWLEDGMENTS}

We acknowledge funding from the Department for Employment and Learning (DEL) Northern Ireland and the Research Challenge Fund from Ulster University.

\section{ABBREVIATIONS}

MALDI matrix-assisted laser desorption/ionization

DESI desorption electrospray ionization

FTICR-MS Fourier transform ion cyclotron resonance mass spectrometry

OTCD on-tissue chemical derivatization

$\mathrm{CD} \quad$ chemical derivatization

25- $(\mathrm{OH})-\mathrm{D}_{3} \quad$ 25-hydroxyvitamin $\mathrm{D}_{3}$

$1,25-(\mathrm{OH})_{2}-\mathrm{D}_{3} \quad 1 \alpha, 25$-dihydroxyvitamin $\mathrm{D}_{3}$

MSI mass spectrometry imaging

\section{REFERENCES}

(1) Fleet, J. C. The role of vitamin D in the endocrinology controlling calcium homeostasis. Mol. Cell. Endocrinol. 2017, 453, 3645 .

(2) Nair, R.; Maseeh, A. Vitamin D: The "sunshine" vitamin. J. Pharmacol. Pharmacother. 2012, 3, 118-125.

(3) Holick, M. F.; Binkley, N. C.; Bischoff-Ferrari, H. A.; Gordon, C. M.; Hanley, D. A.; Heaney, R. P.; Murad, M. H.; Weaver, C. M. Evaluation, treatment, and prevention of vitamin D deficiency: an Endocrine Society clinical practice guideline. J. Clin. Endocrinol. Metab. 2011, 96, 1911-1930.

(4) Wagner, C. L.; Greer, F. R. Prevention of rickets and vitamin D deficiency in infants, children, and adolescents. Pediatrics 2008, 122, $1142-1152$.

(5) Doherty, D.; Dvorkin, S. A.; Rodriguez, E. P.; Thompson, P. D. Vitamin D receptor agonist EB1089 is a potent regulator of prostatic "intracrine" metabolism. Prostate 2014, 74, 273-285.

(6) Mathieu, C. Vitamin D and diabetes: where do we stand? Diabetes Res. Clin. Pract. 2015, 108, 201-209.

(7) Gowda, U.; Mutowo, M. P.; Smith, B. J.; Wluka, A. E.; Renzaho, A. M. N. Vitamin D supplementation to reduce depression in adults: meta-analysis of randomized controlled trials. Nutrition 2015, 31, 421-429.

(8) Lerner, P. P.; Sharony, L.; Miodownik, C. Association between mental disorders, cognitive disturbances and vitamin $\mathrm{D}$ serum level: current state. Clin. Nutr. 2018, 23, 89-102.

(9) Bikle, D. D. Vitamin D metabolism, mechanism of action, and clinical applications. Chem. Biol. 2014, 21, 319-329.

(10) Simon, R. R.; Phillips, K. M.; Horst, R. L.; Munro, I. C. Vitamin $\mathrm{D}$ mushrooms: comparison of the composition of button mushrooms (Agaricus bisporus) treated postharvest with UVB light or sunlight. J. Agric. Food Chem. 2011, 59, 8724-8732.

(11) Nölle, N.; Argyropoulos, D.; Ambacher, S.; Müller, J.; Biesalski, H. K. Vitamin D2 enrichment in mushrooms by natural or artificial UV-light during drying. LWT-Food Sci. Technol. 2017, 85, 400-404.

(12) Pike, J. W.; Christakos, S. Biology and mechanisms of action of the vitamin D hormone. Endocrinol. Metabol. Clin 2017, 46, 815-843.

(13) Smith, K. W.; Thompson, P. D.; Rodriguez, E. P.; Mackay, L.; Cobice, D. F. Effects of vitamin D as a regulator of androgen intracrinology in LNCAP prostate cancer cells. Biochem. Biophys. Res. Commun. 2019, 519, 579-584.

(14) Volmer, D. A.; Mendes, L. R. B. C.; Stokes, C. S. Analysis of vitamin $\mathrm{D}$ metabolic markers by mass spectrometry: current techniques, limitations of the "gold standard" method, and anticipated future directions. Mass Spectrom. Rev. 2015, 34, 2-23.

(15) Hedman, C. J.; Wiebe, D. A.; Dey, S.; Plath, J.; Kemnitz, J. W.; Ziegler, T. E. Development of a sensitive LC/MS/MS method for vitamin D metabolites: 1, 25 Dihydroxyvitamin D2\&3 measurement using a novel derivatization agent. J. Chromatogr. B: Biomed. Sci. Appl. 2014, 953-954, 62-67. 
(16) Graeff-Armas, L. A.; Kaufmann, M.; Lyden, E.; Jones, G. Serum 24, 25-dihydroxyvitamin D3 response to native vitamin D2 and D3 Supplementation in patients with chronic kidney disease on hemodialysis. Clin. Nutr. 2018, 37, 1041-1045.

(17) Qi, Y.; Müller, M.; Stokes, C. S.; Volmer, D. A. J. Am. Soc. Mass Spectrom. 2018, 29, 1456-1462.

(18) Cobice, D. F.; Mackay, C. L.; Goodwin, R. J. A.; McBride, A.; Langridge-Smith, P. R.; Webster, S. P.; Walker, B. R.; Andrew, R. Mass spectrometry imaging for dissecting steroid intracrinology within target tissues. Anal. Chem. 2013, 85, 11576-11584.

(19) Cobice, D. F.; Livingstone, D. E. W.; McBride, A.; MacKay, C. L.; Walker, B. R.; Webster, S. P.; Andrew, R. Quantification of $11 \beta$ hydroxysteroid dehydrogenase 1 kinetics and pharmacodynamic effects of inhibitors in brain using mass spectrometry imaging and stable-isotope tracers in mice. Biochem. Pharmacol. 2018, 148, 88-99.

(20) Barré, F. P. Y.; Flinders, B.; Garcia, J. P.; Jansen, I.; Huizing, L. R. S.; Porta, T.; Creemers, L. B.; Heeren, R. M. A.; Cillero-Pastor, B. Derivatization strategies for the detection of triamcinolone acetonide in cartilage by using matrix-assisted laser desorption/ionization mass spectrometry imaging. Anal. Chem. 2016, 88, 12051-12059.

(21) Shariatgorji, M.; Nilsson, A.; Källback, P.; Karlsson, O.; Zhang, X.; Svenningsson, P.; Andren, P. E. Pyrylium salts as reactive matrices for MALDI-MS imaging of biologically active primary amines. J. Am. Soc. Mass Spectrom. 2015, 26, 934-939.

(22) Chacon, A.; Zagol-Ikapitte, I.; Amarnath, V.; Reyzer, M. L.; Oates, J. A.; Caprioli, R. M.; Boutaud, O. On-tissue chemical derivatization of 3-methoxysalicylamine for MALDI-imaging mass spectrometry. J. Mass Spectrom. 2011, 46, 840-846.

(23) Wu, Q.; Comi, T. J.; Li, B.; Rubakhin, S. S.; Sweedler, J. V. Ontissue Derivatization Via Electrospray Deposition for Matrix-Assisted Laser Desorption/Ionization Mass Spectrometry Imaging of Endogenous Fatty Acids in Rat Brain Tissues. Anal. Chem. 2016, 88, 59885995.

(24) Cobice, D. F.; Livingstone, D. E. W.; Mackay, C. L.; Goodwin, R. J. A.; Smith, L. B.; Walker, B. R.; Andrew, R. Spatial Localization and Quantitation of Androgens in Mouse Testis by Mass Spectrometry Imaging. Anal. Chem. 2016, 88, 10362-10367.

(25) Tucker, L. H.; Conde-González, A.; Cobice, D.; Hamm, G. R.; Goodwin, R. J. A.; Campbell, C. J.; Clarke, D. J.; Mackay, C. L. MALDI matrix application utilizing a modified 3D printer for accessible high resolution mass spectrometry imaging. Anal. Chem. 2018, 90, 8742-8749.

(26) Strohalm, M.; Kavan, D.; Novák, P.; Volný, M.; Havlíček, V. mMass 3: a cross-platform software environment for precise analysis of mass spectrometric data. Anal. Chem. 2010, 82, 4648-4651.

(27) Sládková, K.; Houška, J.; Havel, J. Laser desorption ionization of red phosphorus clusters and their use for mass calibration in timeof-flight mass spectrometry. Rapid Commun. Mass Spectrom. 2009, 23, 3114-3118.

(28) Bikle, D. D.; Patzek, S.; Wang, Y. Physiologic and pathophysiologic roles of extra renal CYP27b1: Case report and review. BoneKEy Rep. 2018, 8, 255-267.

(29) Feldman, D.; Krishnan, A. V.; Swami, S.; Giovannucci, E.; Feldman, B. J. The role of vitamin D in reducing cancer risk and progression. Nat. Rev. Canc. 2014, 14, 342-357.

(30) Maguire, O.; Pollock, C.; Martin, P.; Owen, A.; Smyth, T.; Doherty, D.; Campbell, M. J.; McClean, S.; Thompson, P. Regulation of CYP3A4 and CYP3A5 expression and modulation of "intracrine" metabolism of androgens in prostate cells by liganded vitamin D receptor. Mol. Cell. Endocrinol. 2012, 364, 54-64.

(31) Jensen, M. B.; Andersen, C. B.; Nielsen, J. E.; Bagi, P.; Jørgensen, A.; Juul, A.; Leffers, H. Expression of the vitamin D receptor, 25 -hydroxylases, $1 \alpha$-hydroxylase and 24 -hydroxylase in the human kidney and renal clear cell cancer. J. Steroid Biochem. Mol. Biol. 2010, 121, 376-382. 